\title{
PLANEJAMENTO URBANO “OPEN SOURCE”: UM ESTUDO DE CASO NA IDENTIFICAÇÃO DE ÁREAS PARA IMPLANTAÇÃO DE ATERRO SANITÁRIO
}

\author{
R. T. V. FERNANDES ${ }^{1 *}$, B. D. A. SILVEIRA ${ }^{1}$ e M. R. OLIVEIRA ${ }^{2}$ \\ ${ }^{1}$ Universidade Federal Rural do Semiárido - UFERSA, ${ }^{2}$ Universidade Potiguar - UnP \\ rogerio.taygra@ufersa.edu.br*
}

Submetido 15/09/2016 - Aceito 20/12/2017

DOI: $10.15628 /$ holos.2017.5091

\section{RESUMO}

A crescente quantidade de lixo produzida nas áreas urbanas é um problema alarmante pela questão ambiental e de saúde pública. A disposição final adequada desses resíduos se inicia com a escolha de locais adequados, para a instalação dos aterros sanitários. O uso de tecnologias livres permite identificação rápida, confiável e com baixo custo de áreas quando comparada com os métodos tradicionais. O objetivo da pesquisa foi demonstrar que a análise em ambiente SIG livre é uma alternativa viável na identificação de áreas adequadas para a instalação de aterros sanitário, tomando como estudo de caso o município de Grossos/RN. Foram utilizados mapas temáticos gerados partir de dados disponíveis em bancos de dados públicos (gratuitos), com informações sobre os aspectos ambientais, socioeconômicos e operacionais, analisados com base em critérios múltiplos predefinidos, de forma a identificar as áreas mais favoráveis para este fim. O resultado do estudo foi um mapa de aptidão para instalação do aterro sanitário, apontando áreas que totalizam 52,02 ha, onde se terá o menor impacto ambiental e melhor retorno social e econômico, demonstrando a viabilidade do uso de SIG livre para o planejamento urbano, gerando informações para subsidiar tomada de decisões.

PALAVRAS-CHAVE: Geotecnologias, Aterro Sanitário, SIG, Geoprocessamento.

\section{URBAN PLANNING "OPEN SOURCE": A CASE STUDY ON THE IDENTIFICATION OF AREAS FOR DEPLOYMENT OF LANDFILL}

\begin{abstract}
The growing amount of garbage produced in urban areas is an alarming problem for environmental and public health issue. The proper disposal of this waste begins with the choice of suitable locations for the installation of landfill sites. The use of free technologies allows rapid identification, reliable and lowcost areas when comparedwith traditional methods. The goal of the research was to demonstrate that the analysis in GIS environment is a viable alternative in identifying areas suitable for the installation of sanitary landfills, taking as a case study the municipality

of Thick/RN. Thematic
\end{abstract}

maps were generated from

data available in public databases (free), with informatio $\mathrm{n}$ about the environmental, socioeconomic and operational aspects, analyzed with multiple predefined c riteria, in order to identify the most favourable areas for this purpose. The result of the study was a map of suitability for installation of landfill, pointing areas totaling 52.02 ha, where you will have the lowest environmental impact and better social and economic return, demonstrating the feasibility of using GIS to urban planning, generating information to support decision-making.

KEYWORDS: Geotechnologies, Landfill, GIS, Geoprocessing. 


\section{INTRODUÇÃO}

Estima-se que até o ano de $2050,70 \%$ da população mundial estará vivendo em áreas urbanas, conforme JIN et al. (2014). Segundo PROKOP et al. (2011) nas últimas décadas, as zonas urbanas cresceram à uma velocidade 4 vezes superior à sua própria população. $O$ rápido crescimento da população, vinculada a expansão de áreas urbanas, torna premente a necessidade de serviços e infraestrutura adequadas para que as cidades não se tornem inabitáveis. Neste contexto, o planejamento urbano surge como uma alternativa para a criação e desenvolvimento de programas que buscam melhorar a qualidade de vida da população.

De acordo com Silva (2008) a destinação dos resíduos sólidos produzidos nas cidades é um dos grandes desafios a serem solucionados pelos gestores públicos na atualidade e no futuro próximo, especialmente quando consideramos que o volume de resíduos produzidos cresce em uma velocidade maior que a própria população. Diante da relevância do assunto, em agosto de 2010 foi sancionada a Lei Federal $n^{\circ}$ 12.305, conforme Brasil (2010), mais conhecida como Política Nacional dos Resíduos Sólidos, que traz em seu bojo, dentre princípios, instrumentos e diretrizes, a determinação do fim dos chamados "lixões", dando como data limite o mês de agosto do ano de 2014, estabelecendo que todos os resíduos sólidos gerados deverão ser direcionados aos aterros sanitários, construídos de acordo com os padrões normativos.

Quatro anos após a Política Nacional dos Resíduos Sólidos ser sancionada, 41,6\%, dos resíduos sólidos gerados no País ainda são destinados incorretamente, e cerca de 1.559 municípios do País ainda se valem dos lixões para depositar seus resíduos sólidos, de acordo com dados de 2014 da ABRELPE. Esse déficit ocorre em virtude da realidade dos municípios brasileiros, seja por limitação financeira, seja por falta de projeto, politicas públicas ou mesmo iniciativa de seus governantes, inviabilizando assim os projetos de implantação dos aterros sanitários.

Uma alternativa potencial para solucionar o problema da definição de áreas adequadas para instalação dos aterros sanitários é o uso de tecnologias livres e dados gratuitos, apoiando-se em um ambiente de Sistema de Informações Geográficas (SIG), que permite a integração e análise de dados espaciais a partir de múltiplos critérios, auxiliando a tomada de decisão de forma confiável e ágil, reduzindo fatores subjetivos, e com baixo custo quando comparado com os métodos convencionais.

Desta forma, a presente pesquisa tem como objetivo demonstrar que uso de ambiente SIG livre, combinado com dados gratuitos, é uma alternativa viável no planejamento urbano, aplicando estes conceitos na identificação de áreas adequadas para a instalação de um aterro sanitário.

\section{REVISÃO BIBLIOGRÁFICA}

\subsection{Política Nacional de Resíduos Sólidos e os aterros sanitários}

O destino inevitável dos resíduos não reutilizáveis, não recicláveis ou não reaproveitáveis deve ser o aterro sanitário, conforme previsto na legislação. De acordo com Associação Brasileira 
de Normas Técnicas - ABNT (1992) na norma brasileira NBR 8.419, aterro sanitário é uma técnica de disposição de resíduos sólidos urbanos no solo, que não causa danos à saúde pública nem à sua segurança, minimizando os impactos ambientais negativos, utilizando princípios de engenharia para confinar os resíduos sólidos à menor área e volumes possíveis, cobrindo-os com camadas de terra ao final de cada jornada de trabalho, ou em intervalos menores, quando se julgar necessário. Assim, o aterro sanitário é o local onde se executa a técnica do aterro descrita anteriormente.

Segundo Bolton e Curtis (1990) a escolha do local adequado para a construção e operação do aterro sanitário é de importância fundamental, e representa um dos principais desafios para a administração pública, especialmente em nível municipal, por considerar que o local selecionado deve atender satisfatoriamente a critérios sociais, ambientais e económicos. Nesse sentido, Após quase 20 anos tramitando nas casas legislativas, em 02 de agosto de 2010 foi sancionada a Lei $n^{\circ}$ 12.305, que instituiu a Política Nacional de Resíduos Sólidos (PNRS). A partir deste momento, o Brasil passa a ter um marco regulatório na área dos resíduos sólidos, fruto da discussão ampla com instituições privadas, representantes governamentais, ONGs e sociedade civil, e que traz em seu cerne princípios, objetivos, instrumentos e diretrizes para a gestão destes resíduos.

Dentre os principais objetivos da Lei $n^{\circ} 12.305$, destacam-se a redução, reutilização e tratamento de resíduos sólidos, além da destinação final ambientalmente adequada dos rejeitos. A lei mesma determinou 2 de agosto de 2014 como data limite para a extinção dos lixões e instalação dos aterros sanitários, posteriormente sendo prorrogada para o ano de 2019, em virtude da incapacidade dos municípios de atender o disposto na legislação.

O Brasil publicou em 1997 por meio da ABNT NBR 13.896 critérios que definem a localização e instalação dos aterros sanitários, dentre os quais destacam-se a preocupação em provocar o mínimo impacto ambiental possível, a aceitação da instalação por parte da população e adequação ao zoneamento regional. Para que esses critérios sejam atendidos, e desta forma o aterro obtenha o máximo de adequabilidade, a referida norma apresenta as seguintes recomendações:

a) topografia - esta característica é fator determinante na escolha do método construtivo e nas obras de terraplenagem para a construção da instalação, sendo recomendado locais com declividade superior a $1 \%$ e inferior a $30 \%$;

b) geomorfologia e tipos de solos existentes - tais indicações são importantes na determinação da capacidade de depuração do solo e da velocidade de infiltração. Considera-se desejável a existência, no local, de um depósito natural extenso e homogêneo de materiais com coeficiente de permeabilidade inferior a 10-6- $\mathrm{cm} / \mathrm{s}$ e uma zona não saturada com espessura superior a 3,0 m;

c) recursos hídricos - deve ser avaliada a possível influência do aterro na qualidade e no uso das águas superficiais e subterrâneas próximas, assim o aterro deve ser localizado a uma distância mínima de 200 m de qualquer coleção hídrica ou curso de água;

d) vegetação - o estudo macroscópico da vegetação é importante, uma vez que ela pode atuar favoravelmente na escolha de uma área quanto aos aspectos de redução do fenômeno de erosão, da formação de poeira e transporte de odores;

e) acessos - fator de evidente importância em um projeto de aterro, uma vez que são utilizados durante toda a sua operação. Deve-se garantir que o local selecionado possibilite o 
acesso para os veículos que farão o transporte dos resíduos, preferencialmente conectando-se à rede vária existente;

f) tamanho disponível e vida útil - em um projeto, estes fatores encontram-se interrelacionados e recomenda-se a construção de aterros com vida útil mínima de 10 anos;

g) custos - os custos de um aterro têm grande variabilidade conforme o seu tamanho e o seu método construtivo, assim a elaboração de um cronograma físico financeiro é necessária para permitir a análise de viabilidade econômica do empreendimento;

h) distância mínima a núcleos populacionais - deve ser avaliada a distância do limite da área útil do aterro a núcleos populacionais, recomendando-se que esta distância seja superior a $500 \mathrm{~m}$.

\subsection{Geotecnologias, Sensoriamento Remoto e SIG}

As chamadas "geotecnologias" estão cada vez mais presentes no nosso dia a dia. Seja por meio de softwares que permitem a visualização de ruas e locais em qualquer parte do mundo, ou por meio de aplicativos para aparelhos móveis que mostram deslocamentos em tempo real e que permitem encontrar o endereço exato de qualquer ponto de interesse, pode-se afirmar que estamos na era da geoinformação. Não seria exagero afirmar que toda atividade humana tem associada a si uma localização geográfica, ou seja, toda ação humana está vinculada a um local no espaço e um determinado tempo, sendo essa característica a matéria prima das geotecnologias.

Segundo Rosa (2005), as geotecnologias se baseiam na coleta, processamento, análise e oferta de informações com referência geográfica. As geotecnologias são compostas por soluções em hardware, software e peopleware que juntas constituem poderosas ferramentas para tomada de decisões. Dentre as geotecnologias podemos destacar: sistemas de informação geográfica, cartografia digital, sensoriamento remoto, sistema de posicionamento global, aerofotogrametria e a topografia clássica.

\subsubsection{Sensoriamento Remoto}

O termo "sensoriamento remoto", segundo Jenssen (2009) traduz um conjunto de técnicas de coleta de dados que se dá à distância do alvo de interesse, normalmente associada a aquisição de imagens digitais por satélites orbitais, mas na prática engloba também aeronaves, espaçonaves e outros produtos que não somente as imagens de satélites.

Embora a literatura apresente diferentes conceitos para o sensoriamento remoto como citado por Crosta (1993), Novo (1995) e Jenssen (2009), todos eles apontam como característica fundamental, a ideia de um sistema por meio do qual se obtêm informações a respeito dos recursos naturais renováveis e não-renováveis do planeta Terra, pela utilização de sensores colocados em diferentes plataformas. Moura (2007) sintetiza que podemos compreender que o sensoriamento remoto é uma importante ferramenta que permite obter informações sobre os recursos naturais, de forma mais rápida, sendo, a cada dia, aperfeiçoada, a fim de suprir a alta demanda pelo conhecimento da superfície da terra. 


\subsubsection{SIG - Sistemas de Informações Geográficas}

Os SIGs (sistemas de informações geográficas), são bancos de dados digitais que possuem, associados a si, uma localização (dados georreferenciados). Conforme Moreira (2005), estes sistemas possuem como características principais a possibilidade de inserir, integrar e manipular, em um banco de dados comum, informações espaciais provenientes de fontes, como a cartografia, imagem de satélites, dados censitários, cadastro, e modelos numéricos do terreno MNT, e a capacidade de combinar várias informações através de algoritmos de manipulação e análise, bem como de consulta, recuperação e visualização do conteúdo dessa base de dados.

Para Vieira et al. (2006), os SIGs têm modificado a metodologia empregada nas atividades de caracterização ambiental e planejamento de desenvolvimento urbano, tornando-as mais ágeis, ao combinar os avanços da automatização da cartografia e dos sistemas de manipulação de banco de dados. Todavia, como alertado por Silva (2003), a utilização dos SIGs não garante a certeza e a segurança de que o produto final corresponda às alternativas mais adequadas. Isto dependerá fundamentalmente da qualidade do banco de dados utilizado, especialmente no que diz respeito às fontes e as formas de representações geográficas. Destaca - se que a experiência dos técnicos com relação ao assunto abordado é elemento essencial, não sendo estes meros manipuladores de dados em softwares.

\subsubsection{Uso das geotecnologias na seleção de locais para implantação de aterros}

Nos últimos anos houve um aumento no número de estudos relacionados à identificação de áreas para a instalação de aterros sanitários nos municípios brasileiros, e em parte significativas destes estudos, foram utilizados bancos de dados georreferenciados e outras ferramentas geotecnológicas. Podemos citar como exemplos destes estudos os realizados por Frasson et al., (2001); Calijuri, Melo e Lorentz (2002); Silva et al., (2005); Santos e Girardi (2007); Schueler e Mahler (2009).

Este recente interesse na aplicação das geotecnologias para definição de áreas adequadas para a destinação dos resíduos urbanos, reforça a confiabilidade e praticidade destas ferramentas, especialmente se considerarmos que para a instalação desses equipamentos são necessários estudos técnicos, ambientais e socioeconômicos que permitem avaliar uma série de critérios, a fim de minimizar os impactos ambientais.

Guimarães (2000) pesquisou sobre a escolha de prováveis locais para a construção do aterro de resíduos sólidos no Rio de Janeiro, através de uma Carta de Zoneamento Ambiental de Uso Específico. As áreas foram classificadas segundo os critérios de população residente na região, tipo de superfície, uso do solo, vegetação, classificação pedológica, geológica, geomorfológica, hidrológica, distância ao centro produtor de resíduos sólidos e distância às rodovias, assim foi possível determinar de maneira rápida e confiável as áreas mais indicadas para construção do aterro. 


\section{METODOLOGIA}

\section{1 Área de estudo}

Para o desenvolvimento desta pesquisa, tomou-se como como estudo de caso o município de Grossos/RN, situado na mesorregião Oeste Potiguar e na microrregião Mossoró, limitando-se com os municípios de Tibau, Mossoró, Areia Branca e o Oceano Atlântico, abrangendo uma área

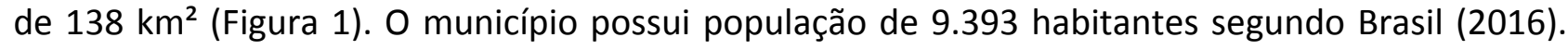
Quanto a gestão de resíduos sólidos, o município destina de maneira irregular seus resíduos para um lixão localizado na Estrada Velha de Grossos, na periferia da cidade (Figura 2), as margens do Rio Apodi-Mossoró, próximo da região de produção de sal, o que causa grandes inconveniente tanto para os produtores, tanto para a população que reside nas proximidades, como mostra a Figura 3.

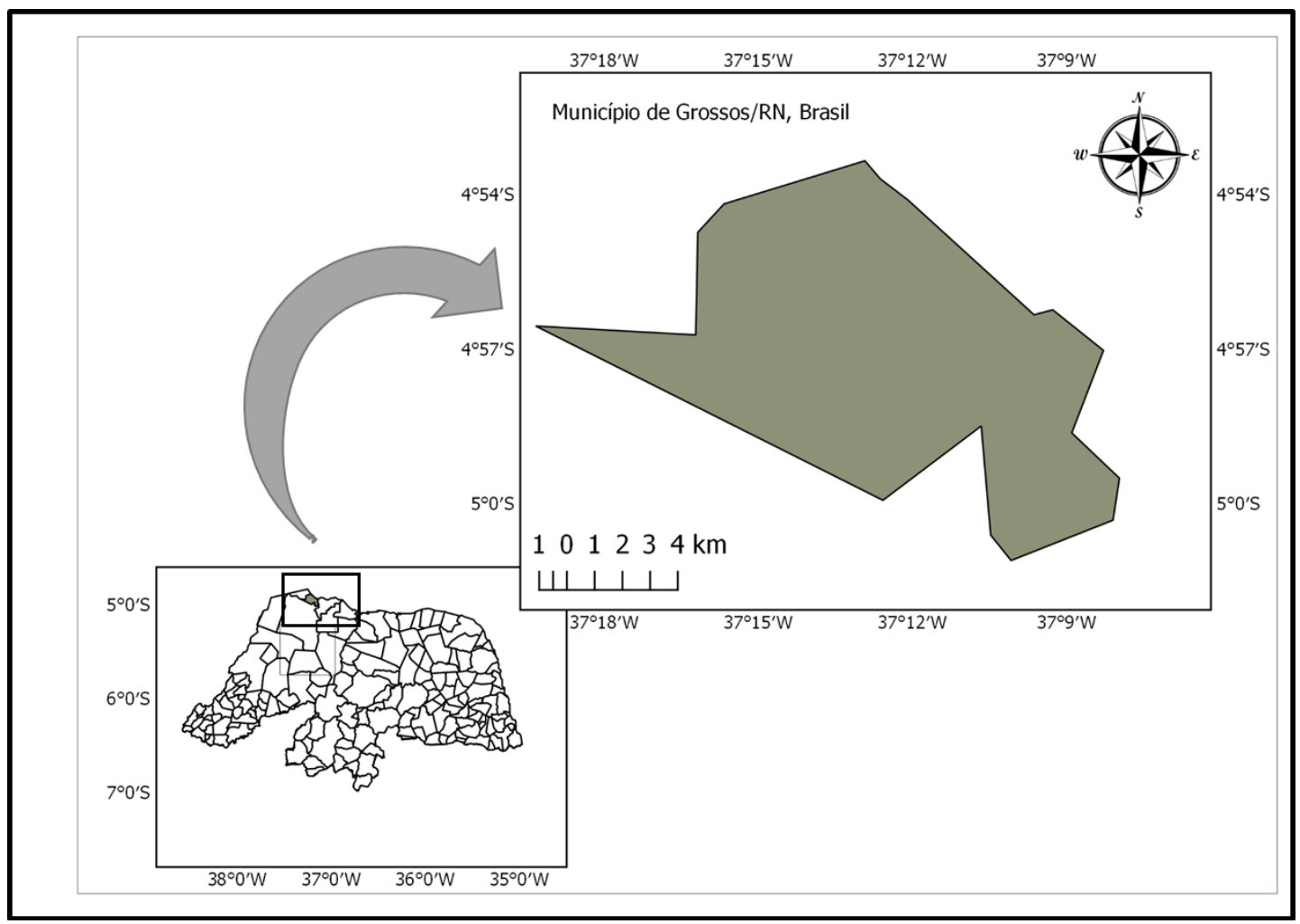

Figura 1: Localização do município de Grossos em relação ao estado do RN. 


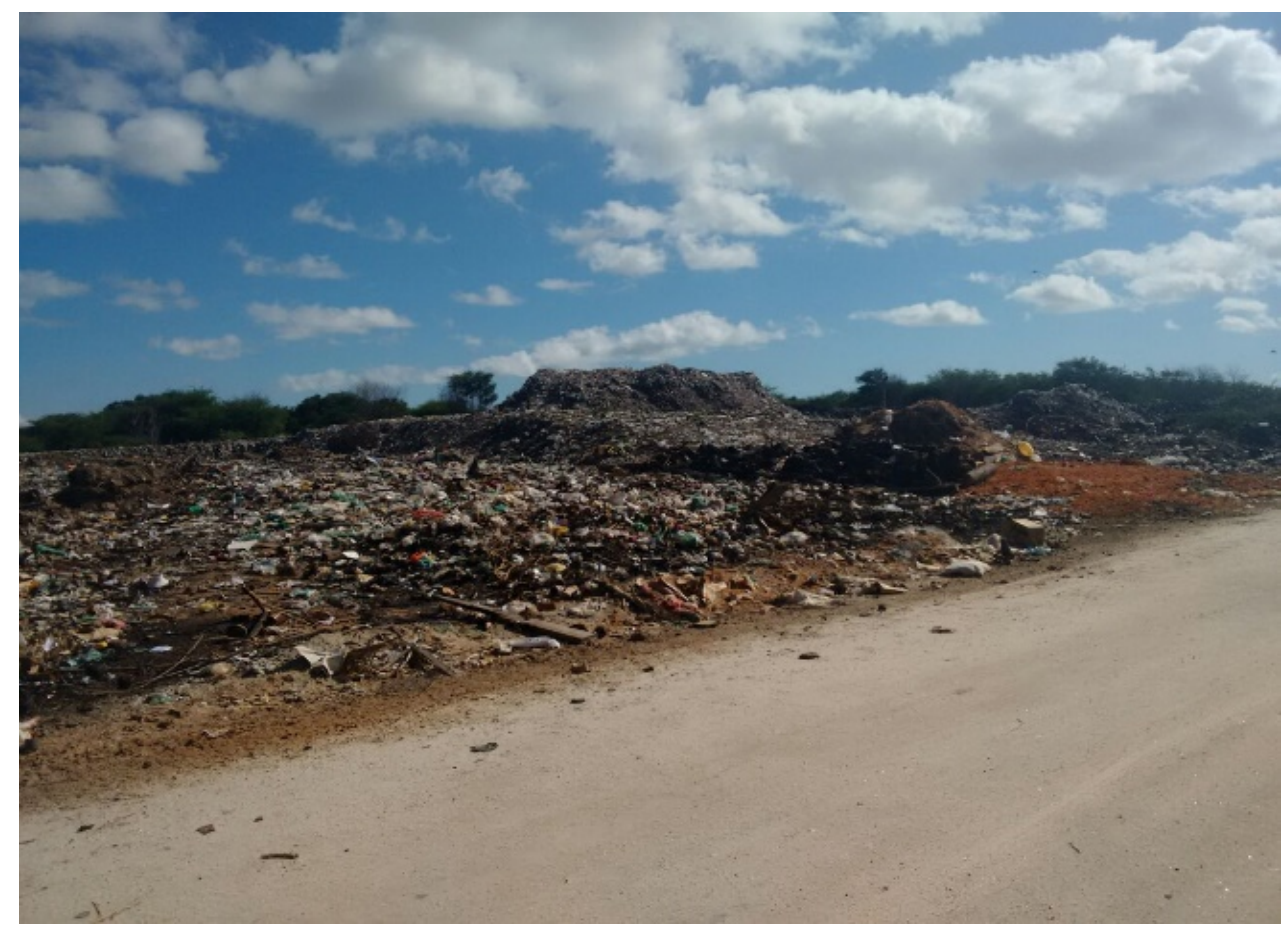

Figura 2: Vista do lixo acumulado a céu aberto no Lixão de Grossos.

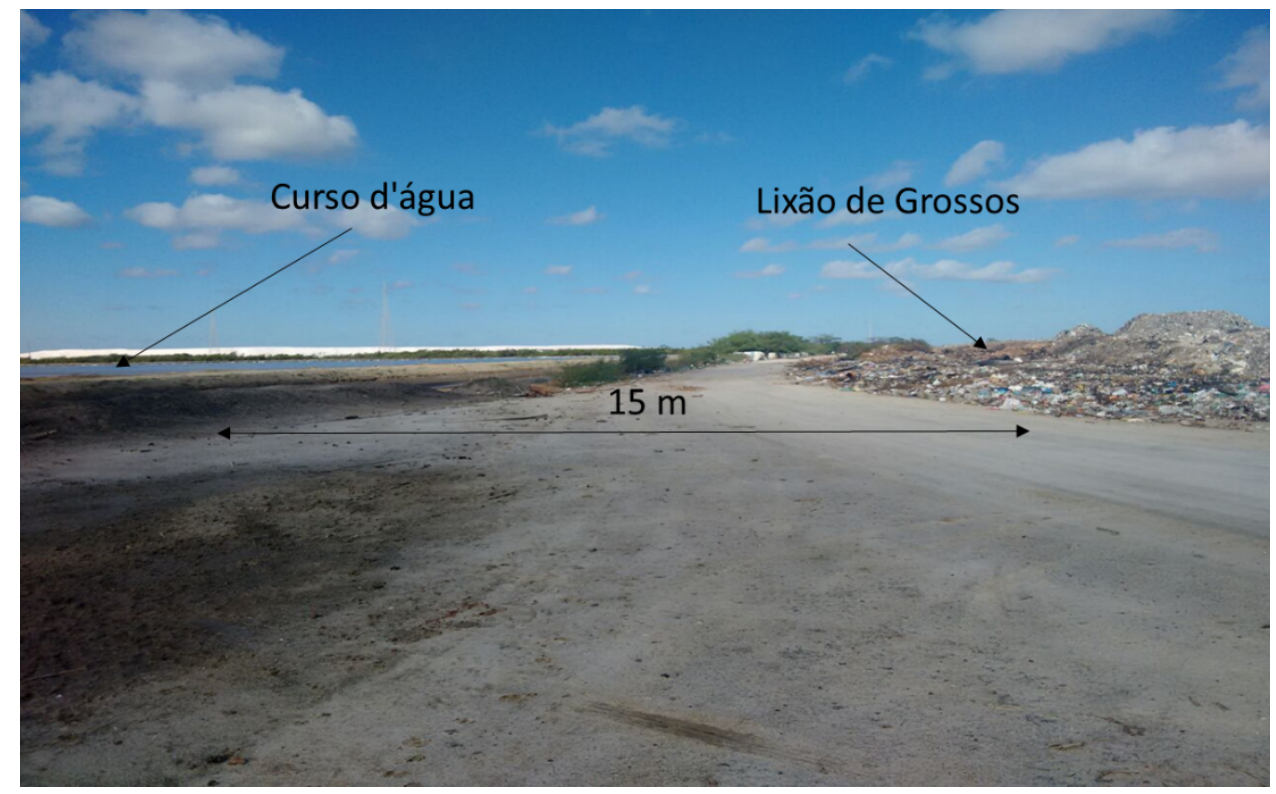

Figura 2: Lixão de Grossos à poucos metros da margem do Rio Apodi-Mossoró e salinas da região.

\subsection{Construção do banco de dados}

Uma das premissas desta pesquisa foi a utilização de dados obtidos gratuitamente, produzidos e disponibilizados por órgãos públicos ou gerados a partir de técnicas de amplo conhecimento, com ferramentas computacionais gratuitas. Desta forma, garantiu-se além da acessibilidade aos dados, possibilidade de replicação e contestação, caso necessário, dos resultados por qualquer interessado. O Quadro 1 , sintetiza os dados utilizados e a fonte para obtenção dos mesmos. 
Quadro 1: Descrição, aplicação e fontes para obtenção dos arquivos vetoriais e matriciais necessários para escolha de áreas aptas para construção de aterro sanitário.

\begin{tabular}{|c|c|c|}
\hline Dados & Aplicação & Fonte \\
\hline $\begin{array}{l}\text { Arquivo vetorial dos } \\
\text { limites municipais }\end{array}$ & $\begin{array}{c}\text { Definição dos limites do } \\
\text { município }\end{array}$ & $\begin{array}{l}\text { IBGE - Instituto Brasileiro de } \\
\text { Geografia e Estatística }\end{array}$ \\
\hline $\begin{array}{l}\text { Arquivo vetorial das } \\
\text { estradas e ruas }\end{array}$ & $\begin{array}{l}\text { Identificação das principais } \\
\text { estradas e vias de acesso }\end{array}$ & $\begin{array}{c}\text { MMA - Ministério do Meio } \\
\text { Ambiente }\end{array}$ \\
\hline $\begin{array}{l}\text { Arquivo vetorial das } \\
\text { unidades geológicas }\end{array}$ & $\begin{array}{c}\text { Identificação da geodiverisdade } \\
\text { e respectiva porosidade }\end{array}$ & $\begin{array}{c}\text { DNPM - Departamento } \\
\text { Nacional de Produção Mineral }\end{array}$ \\
\hline $\begin{array}{l}\text { Arquivo vetorial de } \\
\text { corpos d'água }\end{array}$ & $\begin{array}{c}\text { Identificação dos rios e lagos } \\
\text { (naturais e artificiais) }\end{array}$ & $\begin{array}{c}\text { MMA - Ministério do Meio } \\
\text { Ambiente }\end{array}$ \\
\hline $\begin{array}{l}\text { Arquivo vetorial da } \\
\text { diversidade } \\
\text { pedogenética }\end{array}$ & Identificação dos tipos de solos & $\begin{array}{c}\text { EMBRAPA - Empresa Brasileira } \\
\text { de Pesquisa Agropecuária }\end{array}$ \\
\hline Imagem de radar SRTM & $\begin{array}{l}\text { Criação de Modelo Digital do } \\
\text { Terreno para determinação da } \\
\text { declividade do terreno }\end{array}$ & $\begin{array}{c}\text { EMBRAPA - Empresa Brasileira } \\
\text { de Pesquisa Agropecuária }\end{array}$ \\
\hline Núcleos populacionais & $\begin{array}{c}\text { Vetorizados a partir de imagens } \\
\text { de satélite CBERS-4 }\end{array}$ & $\begin{array}{l}\text { INPE - Instituto Nacional de } \\
\text { Pesquisas Espaciais }\end{array}$ \\
\hline
\end{tabular}

Os mapas das Áreas de Preservação Permanente (APPs) foram obtidos a partir do trabalho de Silveira, Araújo e Silva (2008).

Todos os arquivos foram referenciados ao sistema de referência geodésico Datum SIRGAS 2000, padrão adotado no Brasil desde 25 de fevereiro de 2015. O sistema de projeção horizontal adotado foi a Universal Transversa de Mercator (UTM).

\subsection{Critérios para seleção da área}

A avaliação da aptidão das áreas para instalação do aterro sanitário foi realizada com base em critérios múltiplos que levam em conta aspectos ambientais, socioeconômicos e operacionais. Os critérios de restrição adotados foram definidos com base na norma NBR 13.896 e os trabalhos de Jardim et al. (1995), Nunes (2002), Calijuri, Melo e Lorentz (2002), Born (2013) e Santos (2014), e encontram-se sumarizados no Quadro 2. As restrições relacionadas à proximidade de aeroportos e campos de pouso não foram levados em consideração, pois o município de Grossos não conta com esta infraestrutura.

Quadro 2: Restrições associadas aos critérios ambiental, operacional e socioeconômico.

\begin{tabular}{|c|l|}
\hline Item & \multicolumn{1}{c|}{ Descrição } \\
\hline $\mathbf{1}$ & Restrições associadas ao critério ambiental \\
\hline 1.1 & $\begin{array}{l}\text { Distância mínima de } 200 \mathrm{~m} \text { de qualquer coleção hídrica ou curso } \\
\text { d'água (de acordo com a NBR 13.896/1.997) }\end{array}$ \\
\hline 1.2 & Distância mínima de $200 \mathrm{~m}$ do sistema viário \\
\hline 1.3 & Distância mínima de $200 \mathrm{~m}$ das falhas geológicas \\
\hline 1.4 & Solos de alta permeabilidade e com aptidão agrícola \\
\hline 1.5 & Unidade geológica com permeabilidade máxima de 30\% \\
\hline $\mathbf{2}$ & Restrições associadas ao critério operacional \\
\hline 2.1 & Declividade máxima de 3\% \\
\hline $\mathbf{3}$ & Restrições associadas ao critério socioeconômico \\
\hline 3.1 & $\begin{array}{l}\text { Distância mínima de } 500 \text { m dos distritos - núcleo populacional (de } \\
\text { acordo com NBR 13.896/1997) }\end{array}$ \\
\hline
\end{tabular}




\begin{tabular}{|c|l|}
\hline 3.2 & $\begin{array}{l}\text { Distância mínima de } 500 \mathrm{~m} \text { da cidade sede - área urbanizada (de } \\
\text { acordo com NBR 13.896/1997) }\end{array}$ \\
\hline 3.3 & $\begin{array}{l}\text { Distância mínima de } 500 \mathrm{~m} \text { das sedes das fazendas (de acordo com } \\
\text { NBR 13.896/1997) }\end{array}$ \\
\hline
\end{tabular}

Fonte: Adaptada de Calijuri, Melo e Lorentz (2002).

\subsection{Processamento de dados e álgebra de mapas}

Para o processamento de dados foi utilizado o software QGIS versão 2.8, programa de Sistema de Informação Geográfica com código aberto e licenciado sob a Licença Pública Geral GNU. O QGIS, é um projeto oficial da Open Source Geospatial Foundation (OSGeo), e pode ser utilizado em Linux, Unix, Mac OSX, Windows e Android, trabalhando tanto com dados vetoriais quanto formatos matriciais e apresenta diversas funcionalidades, como visualização, criação, edição, análise de dados e composição de mapas.

Foram gerados mapas temáticos individuais para cada uma das variáveis analisadas, determinando as áreas favoráveis ou com restrições com base nos critérios predefinidos. Após a geração dos mapas individuais, foi aplicada a álgebra de mapas sobre os mesmos, realizando operações de diferença e interseção das áreas consideradas aptas, por meio de operações booleanas, até se chegar a definição de áreas que atendem simultaneamente a todos os critérios.

\section{RESULTADOS E DISCUSSÕES}

\subsection{Avaliação isolada dos critérios}

\subsubsection{Declividade}

A declividade foi o critério de menor restrição para a instalação do aterro sanitário, com $121,45 \mathrm{Km}^{2}$ de área com declividade de até 3\% (Figura 4), que corresponde a 96,39 \% do território.

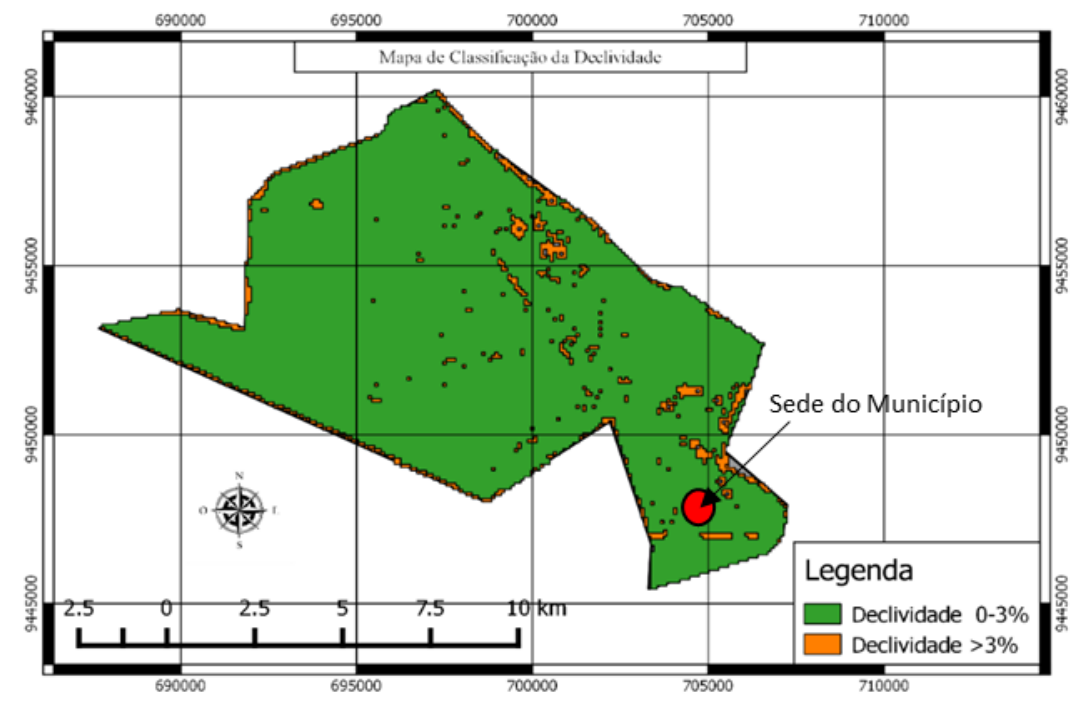


Figura 3: Mapa de classificação de áreas aptas para instalação de aterro sanitário com base na declividade do terreno.

\subsubsection{Unidade geomorfológica}

Quanto a geodiverisdade, foram identificadas 6 unidades geomorfológicas: associadas a tabuleiros costeiros, depósito aluvionar, depósito flúvio lacustre, depósito marinho costeiro, dunas e intercalações de sedimentos síltico-argilosos e quartzo-arenosos (Figura 5). Dentre estas, apenas unidade composta por intercalações de sedimentos síltico-argilosos e quartzo-arenosos (com área correspondente de $9,76 \mathrm{Km}^{2}$ ) possui porosidade inferior a $30 \%$, podendo ser classificada como favorável à instalação de um aterro sanitário.

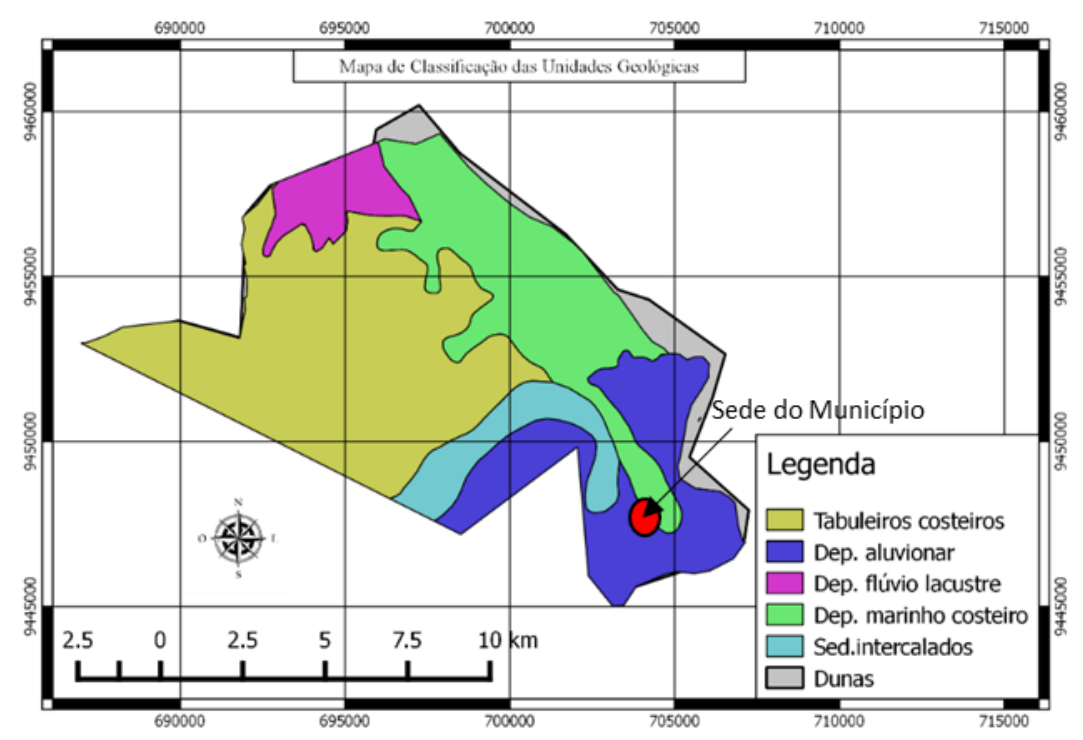

Figura 4: Mapa de classificação de áreas aptas para instalação de aterro sanitário com base na porosidade da unidade geomorfológica.

\subsubsection{Solos}

Os solos da região foram enquadrados em 3 categorias principais, sendo estas, latossolo vermelho, latossolo amarelo e gleissolo sálico sódico (Figura 6). Os latossolos vermelho e amarelo são solos de grande permeabilidade a água, e possuem aptidão agrícola, duas características restritivas para implantação de um aterro sanitário. O gleissolo sálico sódico por sua vez, possuem baixa permeabilidade quando comparado aos lotossolos, e possuem baixo potencial agrícola, desta forma, sendo adequado a instalação de aterros sanitários. 


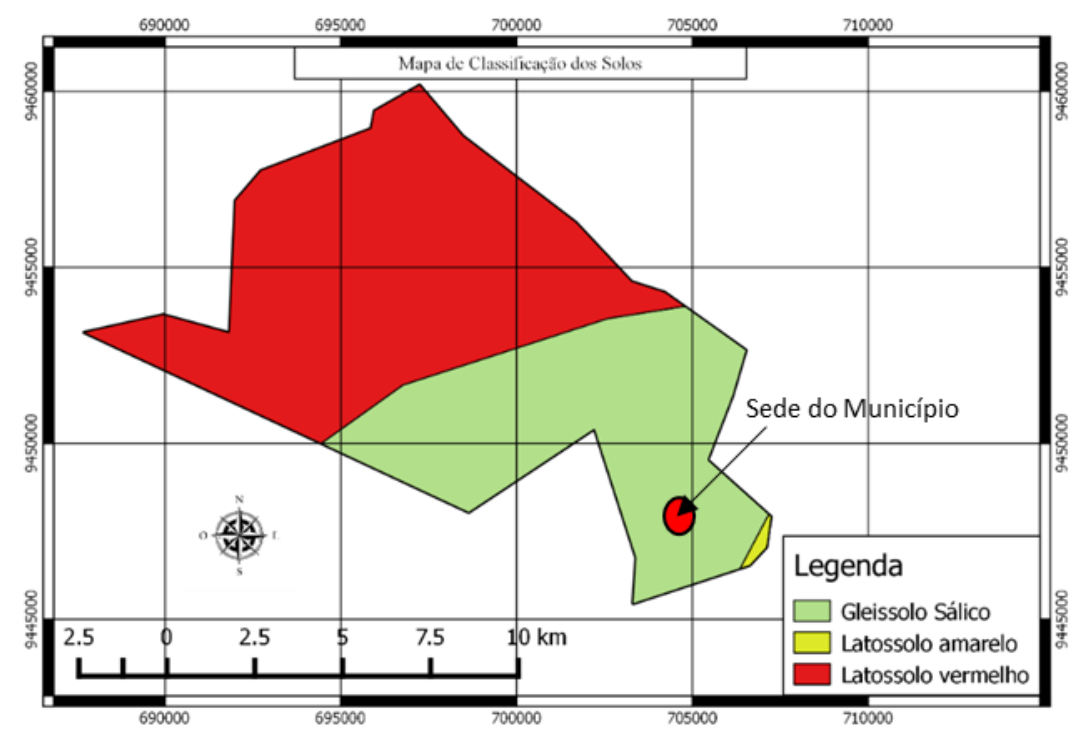

Figura 5: Mapa de classificação de áreas aptas para instalação de aterro sanitário com base no tipo de solo.

\subsubsection{Corpos hídricos}

Um dos critérios mais importantes na definição de áreas para instalação de aterros sanitários é a distância até a rede de drenagem, devido aos riscos de contaminação. O município de Grossos apresenta peculiaridades neste aspecto, pois existem em seu território, além de cursos dágua perenes naturais, rios intermitentes, e grandes lagos salinos artificiais (áreas de produção de sal por evaporação solar). Neste estudo, todas as formas de acumulção de água, naturais ou artificiais, perenes ou intermitentes, e seu entorno (de acordo com o critério definido) foram consideradas como áreas restritas ou inadequadas para a instalação de um aterro sanitário, conforme apresentado na Figura 7.

Os corpos hídricos apresentados na Figura 7 estão em sobreposição das APPs de margens de rio, veredas e parte de manguezais. 


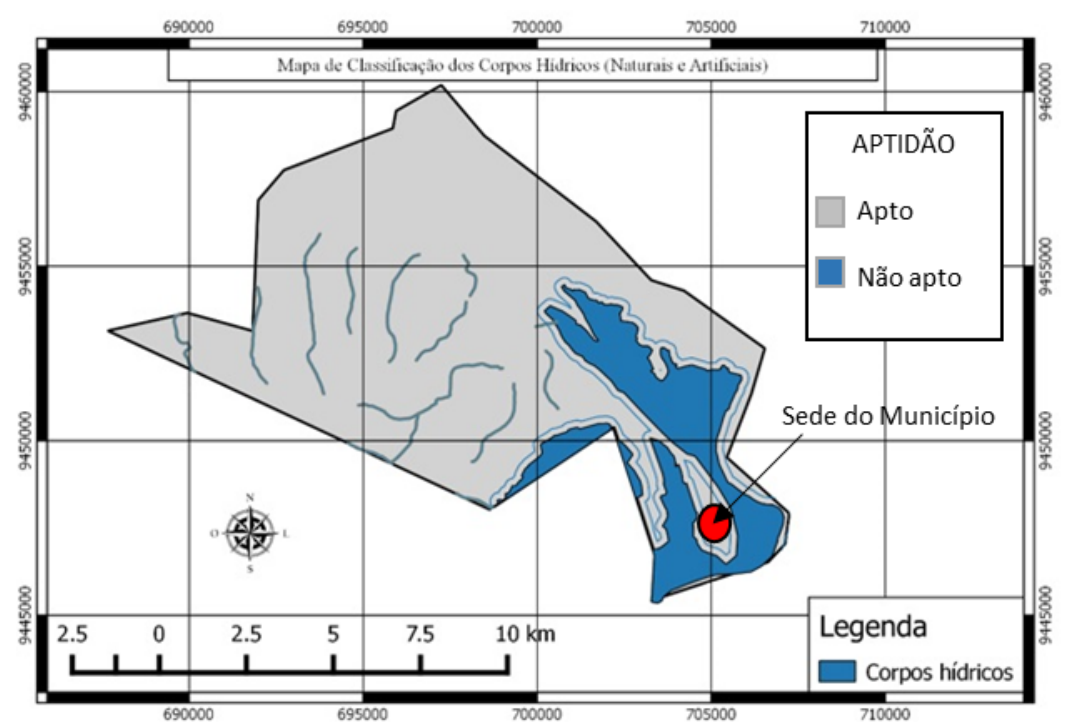

Figura 6: Mapa de classificação de áreas aptas para instalação de aterro sanitário com base distância mínima de corpos hídricos.

\subsubsection{Estradas e vias de acesso}

A distância da estrada até o aterro sanitário é um fator importante, pois indica se a área almejada possui infraestrutura básica para permitir o transporte adequado dos resíduos. De modo geral, assume-se que quanto mais distante das estradas e vias de acesso, mais onerosa será a operação. Por outro lado, a proximidade excessiva do aterro sanitário com a rede viária poderá resultar em poluição visual e desconforto para os usuários do sistema viário. Com base nessa premissa, e utilizando como critério a distância mínima de $200 \mathrm{~m}$ do aterro sanitário até a rede viária, foi possível identificar as áreas favoráveis a sua instalção (Figura 8).

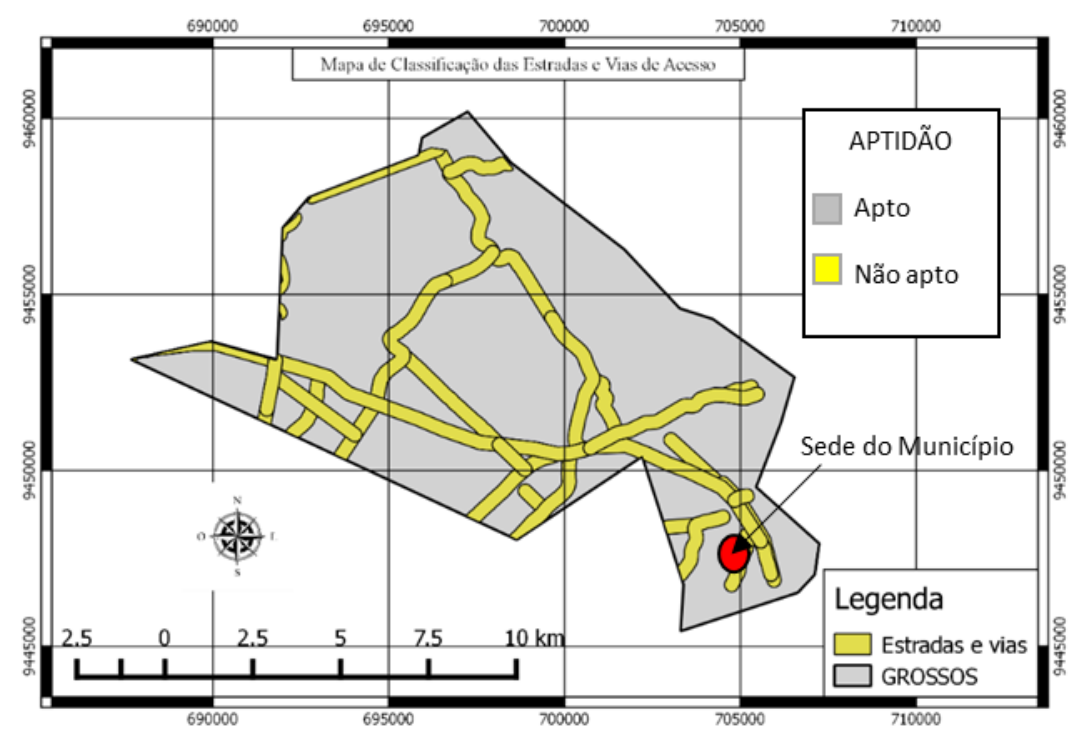


Figura 7: Mapa de classificação de áreas aptas para instalação de aterro sanitário com base na distância até as estradas e vias de acesso.

\subsubsection{Núcleos populacionais (fonte geradora de resíduos)}

Os aterros sanitários devem ser instalados a uma distância tal dos núcleos populacionais que não provoque problemas para a comunidade próxima, como proliferação de doenças, mau cheiro, poluição visual e auditiva. Se por um lado aterros mais distantes possuem menor probabilidade de causar desconforto a população, por outro, os custos de transporte dos resíduos da fonte geradora até o local de disposição final aumentam consideravelmente, podendo chegar até a inviabilizar o empreendimento.

No município de Grossos, os núcleos populacionais não se distribuem de maneira adensada, como o que ocorre nas grandes cidades, mais sim em assentamentos e comunidade espaçadas, o que torna a análise do local adequado para instalação do aterro sanitário mais complexa, pois resulta em áreas adequadas para uma das fontes geradoras e inadequadas para as demais. Com base nas distâncias mínima e máxima da área para instalação dos aterros até os núcleos populacionais, foi possível estabelecer as áreas mais adequadas para cada uma das comunidades (Figura 9).

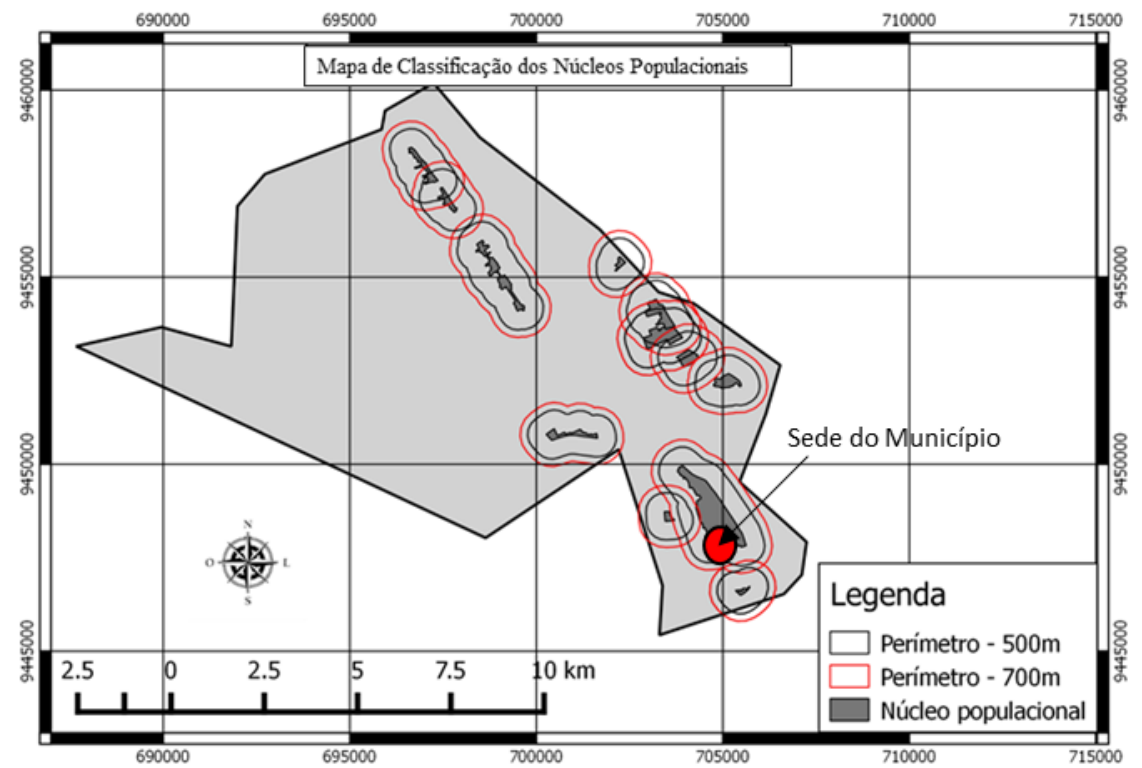

Figura 8: Mapa de classificação de áreas aptas para instalação de aterro sanitário com base distância até os núcleos populacionais.

\subsection{Avaliação combinada dos critérios}

\subsubsection{Identificação das áreas adequadas}

A avaliação da aptidão para instalação de aterros sanitários a partir da análise combinada da declividade, geomorfologia, solos, corpos hídricos, áreas de preservação permanente, estradas e núcleos populacionais do município de Grossos possibilitou a geração de informações geoespacializadas sobre as áreas mais adequadas para esta finalidade. Foram identificadas 6 parcelas adequadas, totalizando uma área de 52,02 hectares (Figura 10). 


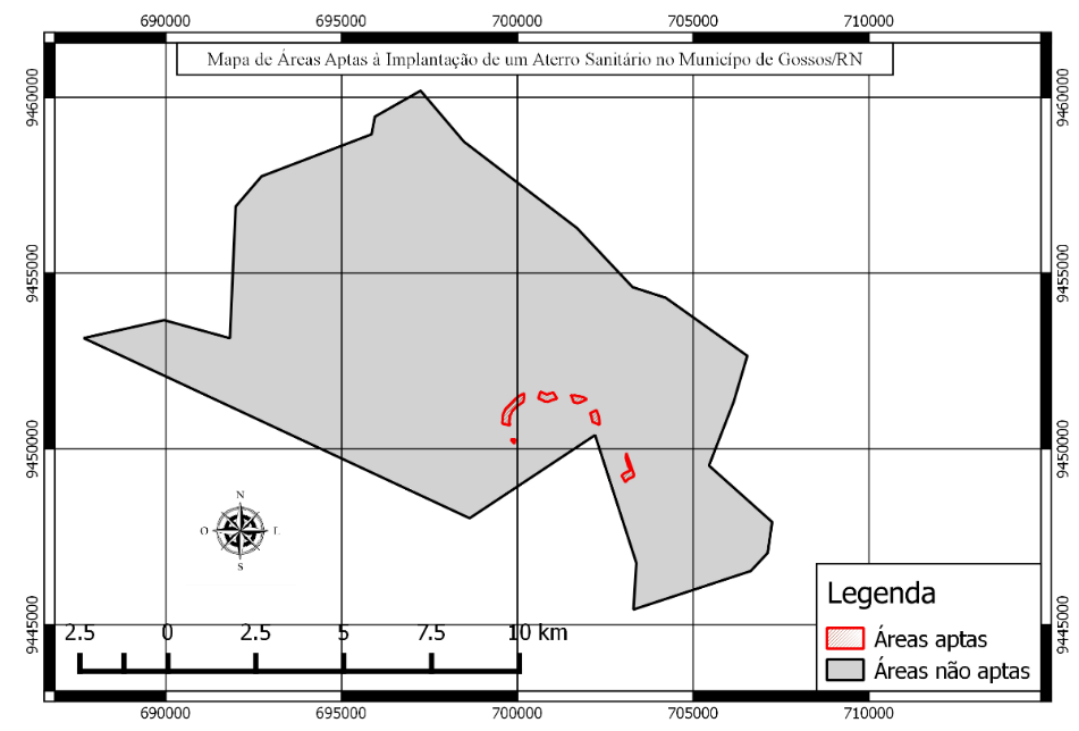

Figura 9: Mapa de áreas favoráveis para instalação de aterro sanitário com base na análise combinada dos critérios.

Cada uma das parcelas identificadas (Figura 11) são semelhantes por não apresentarem nenhuma restrição de acordo com os critérios avaliados, mas diferem entre si quanto a quanto a área disponível (Tabela 1).

Tabela 1: Áreas disponíveis para instalação de aterros sanitários em cada uma das parcelas identificadas.

\begin{tabular}{cc}
\hline Parcela & Área (ha) \\
\hline A & 0,81 \\
\hline B & 19,20 \\
\hline C & 9,54 \\
\hline D & 6,00 \\
\hline E & 6,85 \\
\hline F & 9,80
\end{tabular}




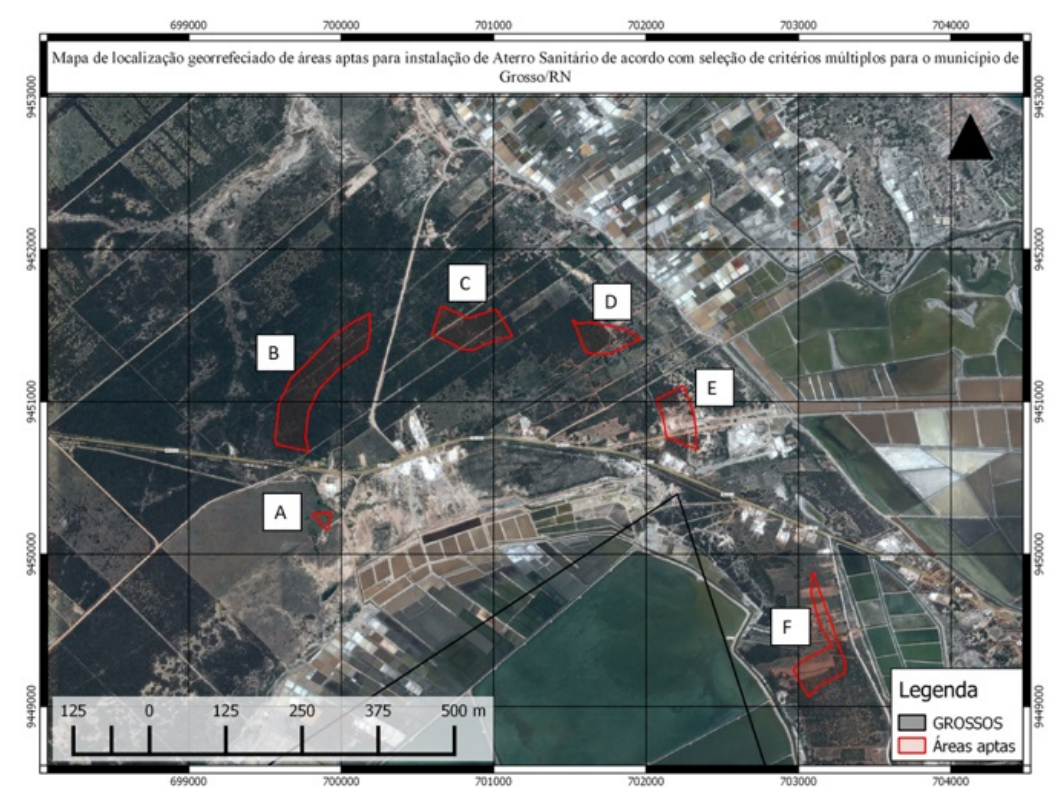

Figura 10: Mapa de identificação das parcelas aptas para instalação de aterro sanitário.

\subsubsection{Viabilidade técnica de implantação em relação ao tamanho das áreas}

Com o objetivo de avaliar se as parcelas aptas para instalação de um aterro sanitário no município de Grossos atende ao quesito tamanho da área para construção das células para aterramento do lixo e instalações de suporte como guarita para inspeção e controle dos veículos, balança para pesagem dos veículos coletores, escritório administrativo e sistema de tratamento de chorume, foi realizado um pré-dimensionamento.

Os critérios utilizados foram primeiramente uma vida útil de 20 anos, crescimento populacional durante esse período estimado com base nos últimos censos demográficos e contagem populacional disponibilizada por Brasil (2016), onde chegou-se a uma população de fim de plano de 12.791 habitantes no ano de 2036, geração per capita de lixo de 0,8 kg/hab.dia, peso especifico dos resíduos compactados no aterro de 0,8 toneladas $/ \mathrm{m}^{3}$ e uma profundidade de 5 metros nas células. Outro dado importante que foi levado em consideração, foi a cobertura total do município na coleta de lixo, cenário otimista em relação ao tema. Chegou-se assim a conclusão que seria necessário uma área de pelo menos 2,12 ha, inviabilizando assim a utilização da parcela A que apresenta uma área de 0,81 ha.

\subsubsection{Aferição in loco dos resultados}

Com o objetivo de validar as informações geradas acerca das áreas, foi realizado visita em campo nas parcelas B, C, D, E e F. A localização foi viabilizada com auxílio de GPS de navegação de 12 canais com as coordenadas centrais das parcelas.

Durante a investigação de campo foi possível observar que a parcela E está situada exatamente sobre o terreno de uma empresa salineira e a parcela F está localizada as margens de uma via de acesso de veículos de carga transportadores de sal marinho e próximo ao seu ponto central está áreas que já foram solicitadas para desmembramentos e loteamentos, inclusive com algumas moradias já construídas, inviabilizando assim o uso destas parcelas para instalação do aterro sanitário. 
Estes dois empecilhos não foram detectados pelo SIG em virtude da desatualização cadastral dos arquivos vetoriais. Mas ficou evidente que uma atualização previa poderia ser realizada através de dados fornecidos pela Secretaria de Urbanismo, Tributação e/ou Meio Ambiente da municipalidade, aumentando significativamente a acurácia do resultado. Assim restaram como opções as parcelas B, C e D.

\subsubsection{Determinação da melhor parcela para implantação do aterro}

As três parcelas restantes avaliadas ( $B, C$ e $D$ ) são similares, próximas da $R N$ 12, rodovia estadual e principal via de acesso ao município, próxima de vias de acesso as comunidades rurais, topografia plana com suave declividade e área suficiente para atender a instalação do aterro. Embora as três opções sejam viáveis indica-se como melhor alternativa a parcela $B$, conforme Figura 12 e memorial descritivo que a descreve na Tabela 2, em virtude de sua área ser maior e ter capacidade de ampliação no futuro.

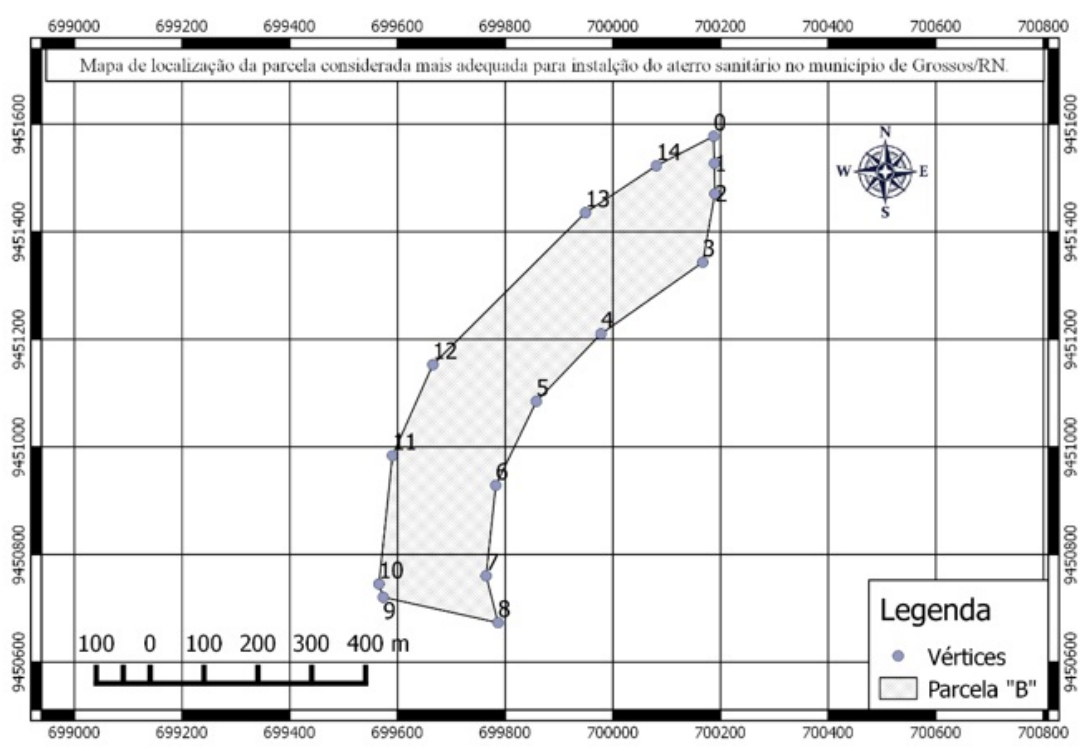

Figura 11: Mapa de localização georreferenciado da parcela "B".

Tabela 2: Memorial descritivo sintético da parcela "B".

\begin{tabular}{ccccccc}
\hline \multirow{2}{*}{ Vértice } & \multicolumn{2}{c}{ Coordenadas } & \multirow{2}{*}{ Lado } & \multicolumn{2}{c}{ Azimutes } & \multicolumn{2}{c}{ Dist. } \\
(m)
\end{tabular}




\begin{tabular}{ccccccc}
\hline Pt1 & 700188.46 & 9451527.00 & Pt1-Pt2 & $179^{\circ} 01^{\prime} 1.85^{\prime \prime}$ & $178^{\circ} 52^{\prime} 52.50^{\prime \prime}$ & 56.58 \\
\hline Pt2 & 700189.42 & 9451470.43 & Pt2-Pt3 & $190^{\circ} 04^{\prime} 4.15^{\prime \prime}$ & $189^{\circ} 54^{\prime} 54.79^{\prime \prime}$ & 129.23 \\
\hline Pt3 & 700166.83 & 9451343.19 & Pt3-Pt4 & $234^{\circ} 49^{\prime} 49.41^{\prime \prime}$ & $234^{\circ} 40^{\prime} 40.06^{\prime \prime}$ & 231.15 \\
\hline Pt4 & 699977.89 & 9451210.03 & Pt4-Pt5 & $223^{\circ} 45^{\prime} 45.70^{\prime \prime}$ & $223^{\circ} 36^{\prime} 36.35^{\prime \prime}$ & 173.62 \\
\hline Pt5 & 699857.81 & 9451084.64 & Pt5-Pt6 & $205^{\circ} 46^{\prime} 46.80^{\prime \prime}$ & $205^{\circ} 37^{\prime} 37.45^{\prime \prime}$ & 173.26 \\
\hline Pt6 & 699782.45 & 9450928.62 & Pt6-Pt7 & $186^{\circ} 06^{\prime} 6.92^{\prime \prime}$ & $185^{\circ} 57^{\prime} 57.57^{\prime \prime}$ & 169.03 \\
\hline Pt7 & 699764.45 & 9450760.55 & Pt7-Pt8 & $165^{\circ} 39^{\prime} 39.66^{\prime \prime}$ & $165^{\circ} 30^{\prime} 30.30^{\prime \prime}$ & 89.97 \\
\hline Pt8 & 699786.73 & 9450673.38 & Pt8-Pt9 & $282^{\circ} 31^{\prime} 31.59^{\prime \prime}$ & $282^{\circ} 22^{\prime} 22.24^{\prime \prime}$ & 218.55 \\
\hline Pt9 & 699573.38 & 9450720.78 & Pt9-Pt10 & $342^{\circ} 11^{\prime} 11.52^{\prime \prime}$ & $342^{\circ} 02^{\prime} 2.16^{\prime \prime}$ & 25.80 \\
\hline Pt10 & 699565.49 & 9450745.35 & Pt10-Pt11 & $5^{\circ} 59^{\prime} 59.19^{\prime \prime}$ & $5^{\circ} 49^{\prime} 49.84^{\prime \prime}$ & 239.93 \\
\hline Pt11 & 699590.51 & 9450983.97 & Pt11-Pt12 & $23^{\circ} 55^{\prime} 55.53^{\prime \prime}$ & $23^{\circ} 46^{\prime} 46.17^{\prime \prime}$ & 184.85 \\
\hline Pt12 & 699665.48 & 9451152.94 & Pt12-Pt13 & $45^{\circ} 06^{\prime} 6.52^{\prime \prime}$ & $44^{\circ} 57^{\prime} 57.17^{\prime \prime}$ & 400.06 \\
\hline Pt13 & 699948.90 & 9451435.29 & Pt13-Pt14 & $56^{\circ} 30^{\prime} 30.42^{\prime \prime}$ & $56^{\circ} 21^{\prime} 21.07^{\prime \prime}$ & 157.90 \\
\hline Pt14 & 700080.58 & 9451522.43 & Pt14-Pt0 & $62^{\circ} 44^{\prime} 45.00^{\prime \prime}$ & $62^{\circ} 35^{\prime} 35.64^{\prime \prime}$ & 119.74 \\
\hline
\end{tabular}

\section{CONCLUSÃO}

Esta pesquisa conseguiu demonstrar a viabilidade do uso de um ambiente SIG livre para no apoio à instalação de aterros sanitários, possibilitando a identificação de uma área apta para esta finalidade no município de Grossos, gerando como produto final um conjunto de informações geoespacializadas (mapas) com potencial para serem utilizadas como subsídios para planejamento urbano e tomada de decisões do poder público. Mais do que isso, este estudo demonstrou ser possível solucionar problemas altamente complexos, envolvendo múltiplos critérios, a partir de uma metodologia simples, informações disponíveis gratuitamente, e um software livre, servindo ao "empoderamento" da sociedade. Ressalta-se ainda que as mesmas ferramentas e raciocínio empregados neste estudo podem, com as devidas adaptações, serem utilizados para identificação de áreas adequadas para instalação de outros aparelhos públicos, como escolas, hospitais, entrepostos de abastecimento e outros.

\section{REFERÊNCIAS}

ABRELPE - ASSOCIAÇÃO BRASILEIRA DE EMPRESAS DE LIMPEZA PÚBLICA E RESÍDUOS ESPECIAIS: Panorama dos resíduos sólidos no Brasil. 2014.

ASSOCIAÇÃO BRASILEIRA DE NORMAS TÉCNICAS. NBR 8.419: Apresentação de projetos de aterros sanitários de resíduos sólidos urbanos. Rio de Janeiro: ABNT, 1992. 7 p.

. NBR 13896: Aterros de resíduos não perigosos - Critérios para projeto, implantação e operação. Rio de Janeiro: ABNT, 1997. 12 p.

BOLTON, K. F., \& CURTIS, F. A. (1990). An Environmental Assessment Procedure for Siting Solid Waste Disposal Sites. Environmental Impact Assessment Review 38, vol. 10, n. 3.

BORN, V. (2013). Avaliação da aptidão de áreas para a instalação de aterro sanitário com o uso de ferramentas de apoio à decisão por múltiplos critérios. (Monografia de Graduação), UNIVATES, Lajeado/RS.

BRASIL. Lei no 12.305, de 2 de agosto de 2010. Lex: Política Nacional de Resíduos Sólidos.

BRASIL. IBGE. Grossos/RN. (2016). Recuperado de http://cidades.ibge.gov.br/painel/populacao.php?codmun=240440 
. IBGE. Instituto Brasileiro de Geografia e Estatística. Pesquisa Nacional de Saneamento Básico, 1989/2008.

CALIJURI, L. M., MELO, A. L. de O., \& LORENTZ, F. J. (2002). Identificação de áreas para implantação de aterros sanitários com uso de análise estratégica de decisão. Informação pública, v. 4, n. 2, 231-250.

CROSTA, A. P. (1992). Processamento digital de imagens de sensoriamento remoto. Campinas/SP: Unicamp, 170.

FRASSON, A. R., WATZLAWICK, L. F., MADRUGA, P. R. de A., \& SCHOENINGER, E. R. (2001). Avaliação de áreas propícias à instalação de aterros sanitários utilizando técnicas de geoprocessamento em sistemas eletroquímicos. Revista Ciências Exatas e Naturais, v. 3, n. 1, 88.

GUIMARÃES, L. T. (2000). Utilização do sistema de informação geográfica (sig) para identificação de áreas potenciais para disposição de resíduos na bacia do paquequer, município de Teresópolis - RJ. (Dissertação de Mestrado), Universidade Federal do Rio de Janeiro.

JARDIM, N. S. et al.(Coord.). (1995). Lixo Municipal: manual de gerenciamento integrado. São Paulo: Instituto de Pesquisas Tecnológicas. 278.

JENSSEN, J.R. (2009). Sensoriamento remoto do ambiente: uma perspectiva em recursos terrestres. São José dos Campos/SP: Parêntese, 679.

JIN, J., GUBBI, J., MARUSIC, S., PALANISWAMI, M. (2014). An information framework for creating a smart city through Internet of things. IEEE Internet Things Journal, 1 (2), 112-121.

MOREIRA, M. A. (2005). Fundamentos do sensoriamento remoto e metodologias de aplicação. São José dos Campos: INPE, 307.

MOURA, L. do C. (2007). A ocupação espaço-temporal dos cafezais no município de Machado, no sul de minas: A relação entre aptidão agrícola da terra e seu uso na atividade cafeeira. (Tese de Doutoramento, Universidade Federal de Lavras). Recuperado de http://repositorio.ufla.br/handle/1/3725? mode=full.

NOVO, E. M. L. de M. (1995). Sensoriamento remoto: princípios e aplicações. São Paulo: Editora Bluncher, 308.

PROKOP, G., JOBSTMANN H., \& SCHÖNBAUER, A. (2011). Overview of best practices for limiting soil sealing or mitigating its effects in EU-27. European Communities, 227.

NUNES, J. O. R. (2002). Uma contribuição metodológica ao estudo da dinâmica da paisagem aplicada a escolha de áreas para a construção de aterro sanitário em Presidente Prudente/SP. (Tese de Doutoramento, Universidade Estadual Paulista, Presidente Prudente).Recuperado de http://repositorio.unesp.br/handle/11449/101450

ROSA, R. (2005). Geotecnologias na Geografia Aplicada. Revista do Departamento de Geografia, 16, 81-90. Recuperado de http://www.cchla.ufrn.br/geoesp/arquivos/artigos/ArtigoAmbienteGeotecnologias.pdf

SANTOS, A. J. S. (2014). Determinação de áreas aptas para instalação de um aterro sanitário. Monografia (Especialização - Geoprocessamento), Universidade Federal de Minas Gerais, Belo Horizonte/MG.

SANTOS, J. S. dos., \& GIRARDI, G. A. (2007). Utilização de geoprocessamento para localização de 
áreas para aterro sanitário no município de Alegrete-RS. In: Simpósio Brasileiro de Sensoriamento Remoto (SBSR), 13. Anais... Florianópolis: INPE, 2007. Artigos, p. 5491-5498. Recuperado de http://marte.sid.inpe.br/col/dpi.inpe.br/sbsr@80/2006/11.15.19.52/doc/5491-5498.pdf

SCHUELER, A. S. de., \& MAHLER, C. (2009). Avaliação de áreas utilizadas para disposição de resíduos sólidos urbanos. Revista Brasileira de Ciências Ambientais, v. 13, n. 2, 18-25. Recuperado de http://abes-dn.org.br/publicacoes/rbciamb/PDFs/13-05_RBCIAMB-N13-Ago2009-Materia03_artigos208.pdf

SILVA, A. de B. (2003). Sistemas de informações geo-referenciadas: conceitos e fundamentos. Campinas/SP: Editora Unicamp.

SILVA, M. E. de C. (2008). Compostagem de lixo em pequenas unidades de tratamento. Viçosa, MG: CPT.

SILVA, R. F. da., Cançado, C. J., LORANDI, R., GALIANO, V. A., \& MOREIRA, M. A. A. (2005, out.). Aplicação metodológica para seleção de áreas para disposição de resíduos sólidos industriais cerâmicos. Estudo de caso: Porto Ferreira - SP. Geociências, v. 24, n. 3, 305-317. Recuperado de http://www.revistageociencias.com.br/24_3/Artigo 7.pdf

SILVEIRA, B. D. A., ARAúJO, D. R., \& SILVA, P. C. M. da. (2008, julho). Mapeamento das áreas de preservação permanente do município de Grossos, RN. Revista Caatinga, v. 21, n. 3, 206-213. Recuperado de http://periodicos.ufersa.edu.br/revistas/index.php/sistema/article/download/654/370

VIEIRA, T. G. C., ALVES, H. M. R., LACERDA, M. P. C., VEIGA, R. D., \& EPIPHANIO, J. C. N. (2006). Crop parameters and spectral response of coffee (Coffea arabica L.) areas within the state of Minas Gerais, Brazil. Coffee Science, v.1, n.2, 111-118. 